Rev. Biol. Neotrop. 6(2):1-14, 2009

\title{
RESCIMENTO E ALOCAÇÃo de FItomASSA DE CINCO GRAMÍNEAS forrageiras em condições de Cerrado
}

\author{
Tomás de Aquino Portes \\ Universidade Federal de Goiás, Instituto de Ciências Biológicas, Caixa Postal 131, Goiânia, \\ 74001-970, Goiás, Brasil; e-mail: portes@icb.ufg.br
}

\section{Sabrina Isabel Costa de Carvalho}

Embrapa Hortaliças, Brasília, Rodovia Brasília/Anápolis BR 060 km 9, Caixa Postal 218, Gama, 70351-970, Distrito Federal, Brasil; e-mail: sabrina@cnph.embrapa.br

\begin{abstract}
Resumo: Gramíneas forrageiras são espécies dominantes nas pastagens brasileiras, destacando-se entre elas Brachiaria decumbens, B. brizantha cv. Marandu e Panicum maximum cv. Colonião, Tanzânia e Mombaça. A fim de aumentar o conhecimento relativo ao crescimento dessas forrageiras, bem como da partição de matéria seca entre os seus diferentes órgãos aéreos em diferentes épocas de desenvolvimento foi conduzido o presente trabalho. Empregou-se delineamento experimental de blocos ao acaso com cinco tratamentos (capins) e quatro repetições. B. decumbens foi a que mais produziu perfilhos (NP). Até 55 dias após a emergência (DAE), Mombaça foi a forrageira que mais produziu matéria seca total (MST); porém, a partir de $62 \mathrm{DAE}$, as produções de todas as espécies não diferiram estatisticamente. Mombaça apresentou o maior índice de área foliar (IAF). A alocação de fitomassa incorporada como matéria seca de colmos (MSC) foi maior em relação àquela direcionada para a produção de matéria seca de folhas verdes (MSFV), a partir de 41 DAE para $B$. decumbens, cv. Colonião e Tanzânia, 55 DAE para Mombaça e 62 DAE para B. brizantha. As taxas de crescimento da cultura (TCC) máximas instantâneas para os capins foram alcançadas aos $62 \mathrm{DAE}$, sendo: $B$. decumbens 37,1 $\mathrm{g} \mathrm{m}^{-2} \mathrm{dia}^{-1}$, B. brizantha - 49,2 $\mathrm{g} \mathrm{m}^{-2} \mathrm{dia}^{-1}$, cv. Colonião - 54,71 $\mathrm{g} \mathrm{m}^{-2} \mathrm{dia}^{-1}$, cv. Tanzânia - 55,7 $\mathrm{g} \mathrm{m}^{-2} \mathrm{dia}^{-1}$ e cv. Mombaça - 45,4 $\mathrm{g} \mathrm{m}^{-2} \mathrm{dia}^{-1}$.
\end{abstract}

Palavras-chave: Análise de crescimento, Brachiaria, matéria seca, Panicum, taxa assimilatória líquida.

\section{Growth and phytomass allocation of five forage grasses under Brazilian Cerrado conditions}

ABstRAct: Forage grasses are dominant species in Brazilian pastures, among which we can mention Brachiaria decumbens, B. brizantha cv. Marandu, Panicum maximum cv. Colonião, Tanzania, and Mombaça. The present study was carried out to better understand the growth of these forage species as well the partitioning of dry mass among the different organs of the canopy at different stages of their development. A completely randomized block design was used with five treatments and four repetitions. $B$. decumbens produced the highest number of tillers (NT). Mombaça produced the highest total dry mass (TDM) up to 55 days after emergence (DAE), but from 62 DAE on the productions of all the species did not differ statistically. Mombaça had the highest leaf area index (LAI). The allocation of phytomass incorporated as stem dry matter (SDM) was higher than that allocated to the production of dry matter of green leaves (DMGL), from $41 \mathrm{DAE}$ for $B$. decumbens, P. maximum cv. Colonião and Tanzania, 55 DAE for cv. Mombaça, and 62 DAE for $B$. brizantha. The maximum instantaneous crop growth rates (CGR) were achieved at $62 \mathrm{DAE}:$ B. decumbens $-37.1 \mathrm{~g} \mathrm{~m}^{-2}$ day $^{-1}$, B. brizantha $-49.2 \mathrm{~g} \mathrm{~m}^{-2}$ day-1, P. maximum $\mathrm{cv}$. Colonião - $54.7 \mathrm{~g} \mathrm{~m}^{-2}$ day ${ }^{-1}$ cv. Tanzania - $55.7 \mathrm{~g} \mathrm{~m}^{-2}$ day $^{-1}, \mathrm{cv}$. Mombaça - $45.4 \mathrm{~g} \mathrm{~m}^{-2}$ day $^{-1}$.

Key words: Brachiaria, dry matter, growth analysis, net assimilation rate, Panicum. 


\section{INTRODUÇÃo}

s pastagens são consideradas
como a fonte mais barata e eco-
nomica, em termos de quantidade e qualidade, para satisfazer as necessidades alimentares do rebanho animal.

Na Região Centro-Oeste, a fonte de alimentos utilizada na pecuária em todas as fases de exploração é basicamente constituída pelas pastagens. Gramíneas são as principais forrageiras nos Cerrados, predominando as braquiárias. Entre as gramíneas forrageiras mais cultivadas nesta região, até 1985 , segundo a distribuição relativa aproximada realizada por Zimmer \& Côrrea (1985), encontravam-se Brachiaria decumbens, sendo a mais plantada (55\%), B. brizantha $(20 \%)$, B. humidicola entre outras (10\%), Panicum maximum cv. Colonião (8\%), P. maximum cv. Tanzânia, Tobiatã, Vencedor (2\%), Andropogon e outras espécies (5\%), todas gramíneas $\mathrm{C} 4$.

B. decumbens foi a mais disseminada no início da ocupação das áreas com pastagens nos Cerrados, nas décadas de 1960 a 1980, normalmente semeada juntamente ou após o semeio do arroz, cultivado após as derrubadas, em aberturas de novas áreas para a agropecuária. Em decorrência de severos ataques de cigarrinha das pastagens (Deois flavopicta Stal), B. decumbens foi gradualmente sendo substituída por $B$. brizantha, que atualmente ocupa a maior parte das áreas com pastagens nos Cerrados (Bernardo et. al., 2003; Boddey et al., 2004), sozinha ou associada a B. decumbens. Esta última, por ser estolonífera, cresce nos espaços deixados por B. brizantha, que é cespitosa.

Diversos trabalhos relatam avaliações de pastagens cultivadas; porém, a grande maioria considera apenas a produção de matéria seca total (MST) obtida ao final de algum período de tempo (Andrade et al., 1996; Canto et al., 2008; Gerdes et al., 2000; Gomide \& Gomide, 1996), às vezes inviabilizando a definição, com algum grau de confiabilidade, da melhor época de pastejo do gado sem prejudicar o crescimento do pasto.

Quantificar a real produção de forragem ao longo do ciclo é muito importante, pois assim pode-se estimar, por intermédio de modelos matemáticos propostos, o crescimento da planta em termos de matéria seca e taxas de produção em determinada data, de maneira a melhorar a eficiência de sua utilização pelos animais. Permite, ainda, calcular a taxa de lotação, estimar a quantidade de forragem consumida, do inicio ao término do pastejo, bem como estimar a produtividade animal (Estrada et al., 1991; Portes et al., 2000; Portes et al., 2003).

Embora seja uma técnica clássica (Blackman, 1919), a análise de crescimento de plantas ainda é de grande utilidade na determinação das partições de fotossintatos entre os vários órgãos das plantas, fornecendo subsídio para quem trabalha visando produção de grãos ou forragem, auxiliando na seleção dos melhores genótipos para tais finalidades. É, ainda, uma técnica que requer poucos recursos instrumentais, sendo, portanto, de baixo custo, tornando-se uma excelente ferramenta para pesquisadores de países em desenvolvimento.

A fim de aumentar o conhecimento relativo ao crescimento, bem como à partição de matéria seca entre os diferentes órgãos aéreos, em diferentes épocas do desenvolvimento de $B$. decumbens, B. brizantha cv. Marandu e P. maximum cv. Colonião, Tanzânia e Mombaça, desenvolveu-se o presente experimento. Propõe-se, também, apresentar equações de regressão, ou modelos matemáticos, que permitam estimar número de perfilhos (NP), índice de área foliar (IAF), matéria seca de folhas verdes (MSFV), matéria seca de colmos (MSC) e matéria seca total (MST), em qualquer data, ao longo da ontogenia das referidas espécies. Os resultados podem auxiliar na tomada de decisão pelo produtor ao procurar escolher aquela espécie que melhor atenda aos seus anseios, tanto no aspecto de produção de forragem como de matéria seca em plantio direto.

\section{Materiais e métodos}

O experimento foi conduzido na área experimental da Escola de Veterinária da Universidade Federal de Goiás, em Goiânia, $16^{\circ} 41^{\prime} \mathrm{S}$ e $49^{\circ} 17^{\prime} \mathrm{W}$, altitude de $730 \mathrm{~m}$.

O solo da área experimental é do tipo Latossolo Vermelho-Escuro. As características químicas do solo, antes do experimento, eram: $\mathrm{pH}\left(\mathrm{CaCl}_{2}\right)$ 5,2; $\mathrm{P}$ disponível (Mehlich I) 
$-2,3 \mathrm{mg} \mathrm{kg}^{-1} ; \mathrm{K}-50 \mathrm{mg} \mathrm{kg}^{-1} ; \mathrm{Ca}-5,7 \mathrm{cmol}_{\mathrm{c}}$ $\mathrm{kg}^{-1} ; \mathrm{Mg}-0,5 \mathrm{cmol}_{\mathrm{c}} \mathrm{kg}^{-1}$; capacidade de troca catiônica - 9,4 $\mathrm{cmol}_{\mathrm{c}} \mathrm{kg}^{-1}$.

No preparo do solo, foi aplicada uma gradagem com grade aradora visando incorporar os restos vegetais e destruir os cupinzeiros. Depois, foi utilizado arado de aiveca com o objetivo de enterrar os restos vegetais a uma profundidade de até $0,40 \mathrm{~m}$ para dificultar a brotação ou a germinação de sementes da vegetação nativa. As adubações de correção foram feitas com aplicação de $350 \mathrm{~kg} \mathrm{ha}^{-1}$ da fórmula 4-30-10, acrescidos de $30 \mathrm{~kg} \mathrm{ha}^{-1} \mathrm{da}$ mistura de micronutrientes FTE BR 12 e $20 \mathrm{~kg}$ ha $^{-1}$ de sulfato de zinco.

O delineamento experimental consistiu de cinco tratamentos, formados pelas gramíneas, em blocos ao acaso, com quatro repetições, totalizando 20 parcelas medindo $50 \mathrm{~m}^{2}(5 \mathrm{~m} \times 10 \mathrm{~m})$ cada. As sementes das cinco forrageiras foram adquiridas no comércio: B. decumbens, B. brizantha Stapf cv. Marandu, P. maximum cv. Colonião, Tanzânia e Mombaça. A semeadura das sementes foi manual, em linhas espaçadas a 0,40 $\mathrm{m}$, das quais duas linhas laterais e $0,5 \mathrm{~m}$ das extremidades foram consideradas como bordaduras. A quantidade de sementes para cada uma das cinco gramíneas utilizada foi de $10 \mathrm{~kg} \mathrm{ha}^{-1}$. A disponibilidade hídrica durante o período do experimento foi adequada, não tendo havido falta nem excesso de chuvas, tendo sido excelente o desenvolvimento visual das forrageiras. No decorrer do experimento, foram efetuadas capinas manuais 30, 60 e 90 dias após a semeadura.

As coletas das plantas iniciaram-se 41 dias após a emergência (DAE) para as análises, prosseguindo até $62 \mathrm{DAE}$, com intervalos de 7 dias entre as coletas. Após os 62 DAE, as coletas foram efetuadas a intervalos de 15 dias até atingir 91 DAE. No total, foram feitas seis amostragens de cada forrageira avaliada, até que atingissem a plena maturação. Para as gramíneas, determinaram-se as datas de emergência, início da floração, floração plena e maturação.

Em cada parcela foi feita uma marcação de $1 \mathrm{~m}$ na linha de plantio para a contagem do NP. Após as contagens, foram coletadas duas plantas de cada parcela (subentendendo- se que cada planta possuía vários perfilhos), ao acaso, as quais foram armazenadas e transportadas em sacos plásticos até que as medições das variáveis de crescimento fossem executadas no laboratório. De cada amostra de planta coletada foram descartadas as raízes e separadas as folhas verdes e os colmos, sendo contado o NP. Em seguida, mediu-se a área foliar em medidor eletrônico (modelo LI 3100 da LI-COR, Nebraska, Estados Unidos). Após a obtenção da área foliar das amostras, as folhas verdes e os colmos foram colocados em sacos de papel, separadamente, e levados a secar em estufa com ventilação forçada a $75^{\circ} \mathrm{C}$.

Foram quantificadas as seguintes variáveis do crescimento das gramíneas: NP por metro linear $\left(\mathrm{NP} \mathrm{m}^{-1}\right)$, IAF $\left(\mathrm{m}^{2}\right.$ de folhas por $\mathrm{m}^{2}$ de terreno), produção de MST da parte aérea (folhas verdes + colmos + inflorescências), produção de MSFV, produção de matéria seca das inflorescências (MSInf) e produção de MSC.

O NP por $\mathrm{m}^{2}\left(\mathrm{NP} \mathrm{m}^{-2}\right)$ foi calculado tomando-se por base o NP $\mathrm{m}^{-1}$ contado dentro da linha de $1 \mathrm{~m}$ previamente demarcada, dividindo-se este valor pelo espaçamento entrelinhas, conforme a equação (Portes et al., 2000):

$$
\left.\mathrm{NP} \mathrm{m^{-2 }}=\left(\mathrm{NP} \mathrm{m}^{-1}\right) \times \text { [espaçamento }(\mathrm{m})\right]^{-1}
$$

Os IAF foram estimados de acordo com a equação:

$\mathrm{IAF}=\left[\mathrm{NP} \mathrm{m^{-1 }} \times\right.$ AF amostra] $\times$ [espaçamento

(m) $x$ perfilho amostra $\left.{ }^{-1} \times 10.000\right]^{-1}$

sendo:

$\mathrm{AF}$ = área foliar da amostra coletada em campo $(\mathrm{cm})$

10.000 para transformar $\mathrm{cm}^{2} \mathrm{em} \mathrm{m}^{2}$

As produções de MSFV e MSC foram estimadas utilizando-se a equação:

MSFV (ou MSC) $=\left(\mathrm{NP} \mathrm{m}^{-1} \times \mathrm{MS}\right.$ amostra $) \times$ [espaçamento $(\mathrm{m}) \times$ perfilhos amostra $\left.\mathrm{m}^{-1}\right]^{-1}$

Aos valores de IAF, MST, MSFV e MSC obtidos foram ajustadas equações e, a partir das equações ajustadas para IAF e MST da parte aérea, determinados os índices fisiológicos instantâneos taxa de crescimento da cultura (TCC) e taxa assimilatória líquida (TAL) pelas equações (Portes \& Castro Júnior, 1991; Portes et al., 2000): 


$$
\begin{gathered}
\mathrm{TCC}=\mathrm{dMST} / \mathrm{dt} \\
\mathrm{TAL}=(\mathrm{dMST} / \mathrm{dt}) / \mathrm{IAF}
\end{gathered}
$$

sendo:

dMST = derivada da equação ajustada aos valores de MST em função do tempo (datas)

\section{Resultados e discussão}

A emergência das cinco gramíneas ocorreu 10 dias após a semeadura e o início da floração foi observado aos 55 DAE para $B$. decumbens e B. brizantha e 62 DAE para $P$. maximum cv. Colonião, Tanzânia e Mombaça. A plena floração, para a maioria das gramíneas avaliadas, ocorreu aos $70 \mathrm{DAE}$; no entanto, para B. brizantha foi verificada somente aos 90 DAE. Nesta data, as demais gramíneas já tinham atingido a maturação (Tabela 1). Quase ao final do ciclo das plantas, ocorreram ventos muito fortes, provocando acamamento nas quatro repetições de P. maximum cv. Mombaça.

Aos valores observados de NP $\mathrm{m}^{-2}$, IAF, MST, MSFV e MSC, em função do tempo, foram ajustadas equações matemáticas. A equação que melhor se ajustou aos dados de $\mathrm{NP} \mathrm{m}^{-2}$ foi a do tipo polinomial exponencial cúbica:

$$
\mathrm{Y}=\mathrm{CEXP}\left(\mathrm{AX}+\mathrm{B} X^{2}+\mathrm{D} X^{3}\right)
$$

Para as demais variáveis, foi a do tipo polinomial exponencial quadrática:

sendo:

$$
\mathrm{Y}=\mathrm{CEXP}\left(\mathrm{AX}+\mathrm{BX}^{2}\right)
$$

$\mathrm{Y}=$ variável dependente (descreve a variação do NP $\mathrm{m}^{-2}$, IAF, MST, MSFV e MSC em função do tempo)

A, B, C e D = coeficientes da equação

$\mathrm{X}=$ variável independente (tempo em DAE)

Os coeficientes de correlação (R) para todos os ajustes variaram entre 0,906 e 0,997, portanto, excelentes correlações (Tabela 2).
B. decumbens foi a espécie que mais produziu perfilhos em todas as datas avaliadas $(\mathrm{p} \leq 0,01)$ (Tabela 3). Aos $41 \mathrm{DAE}$, data da primeira leitura em campo, $B$. decumbens já possuía 500 perfilhos $\mathrm{m}^{-2}$. Permaneceu mais ou menos constante em torno deste valor até os 76 DAE, caindo para 409 aos 91 DAE (Figura 1A, Tabela 4). Todas as demais gramíneas possuíam em torno de 235 perfilhos $\mathrm{m}^{-2}$ aos $41 \mathrm{DAE}$, não diferindo entre si (Tukey 5\%). Apenas $B$. brizantha ganhou perfilhos, chegando a 308 aos 91 DAE. P. maximum cv. Colonião e Tanzânia tiveram seus perfilhos reduzidos, caindo para aproximadamente 208 aos 91 DAE.

A quantidade de perfilhos é uma característica genética de cada espécie, mas pode ser influenciada por densidade e altura das plantas, uma vez que estes parâmetros interferem na porcentagem de penetração de luz em interação com balanço hormonal (Paciullo et al., 2007; Taiz \& Zeiger, 2008). A redução no NP é consequência natural de sua senescência e morte. No caso de B. brizantha, o aumento de NP foi, presumivelmente, decorrente do ciclo mais longo (Tabela 1).

Os valores de IAF para as cinco gramíneas avaliadas mostraram-se elevados, apresentando diferenças entre si aos $48 \mathrm{DAE}$ e $55 \operatorname{DAE}(\mathrm{p} \leq 0,01)$ e aos $91 \mathrm{DAE}(\mathrm{p} \leq 0,01)$, não tendo ocorrido diferenças aos 62 DAE e 76 DAE (Tabela 3 e 4). Não obstante, observando as variações dos IAF entre as datas, apresentados na Tabela 3, na qual se encontram valores originais obtidos em campo, verifica-se que, no geral, cv. Mombaça predominou, com maiores IAF em relação às demais, ficando isto bem evidenciado a partir das equações de regressão, apresentadas na Figura 1B. Embora tenha apresentado o maior NP, B. decumbens, de maneira geral, apresentou os menores IAF.

Tabela 1 - Floração das gramíneas estudadas.

\begin{tabular}{cl}
\hline DAE $^{1}$ & \multicolumn{1}{c}{ Situação das plantas } \\
\hline 55 & Início da floração de Brachiaria decumbens e B. brizantha \\
62 & Início da floração de Panicum maximum cv. Colonião, Tanzânia e Mombaça \\
70 & Plena floração de B. decumbens e de P. maximum cv. Colonião, Tanzânia e Mombaça \\
90 & Plena floração de B. brizantha \\
\hline
\end{tabular}

${ }^{1} \mathrm{DAE}=$ dias após a emergência.

A emergência de todos os capins ocorreu 10 dias após a semeadura. 


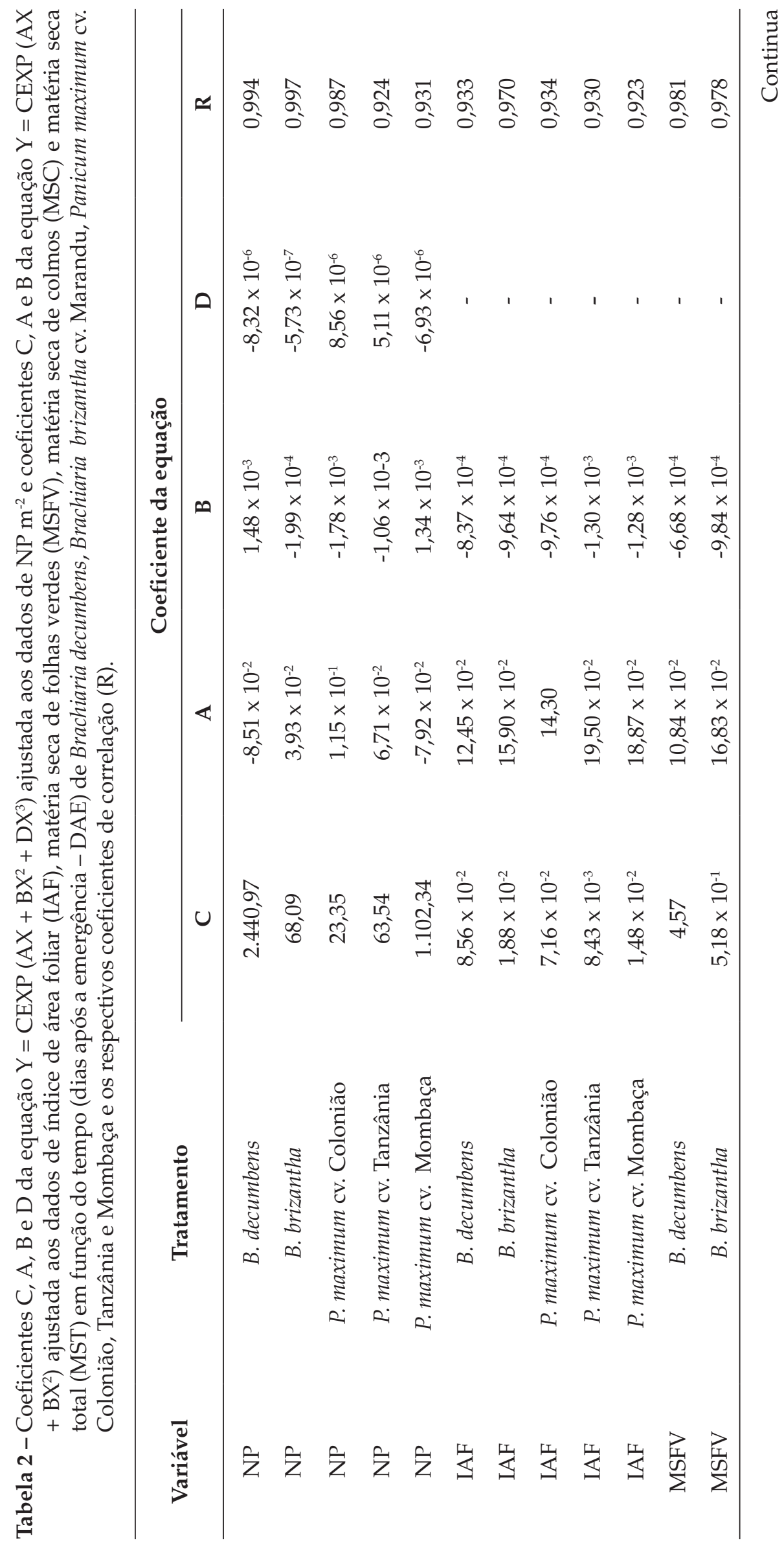




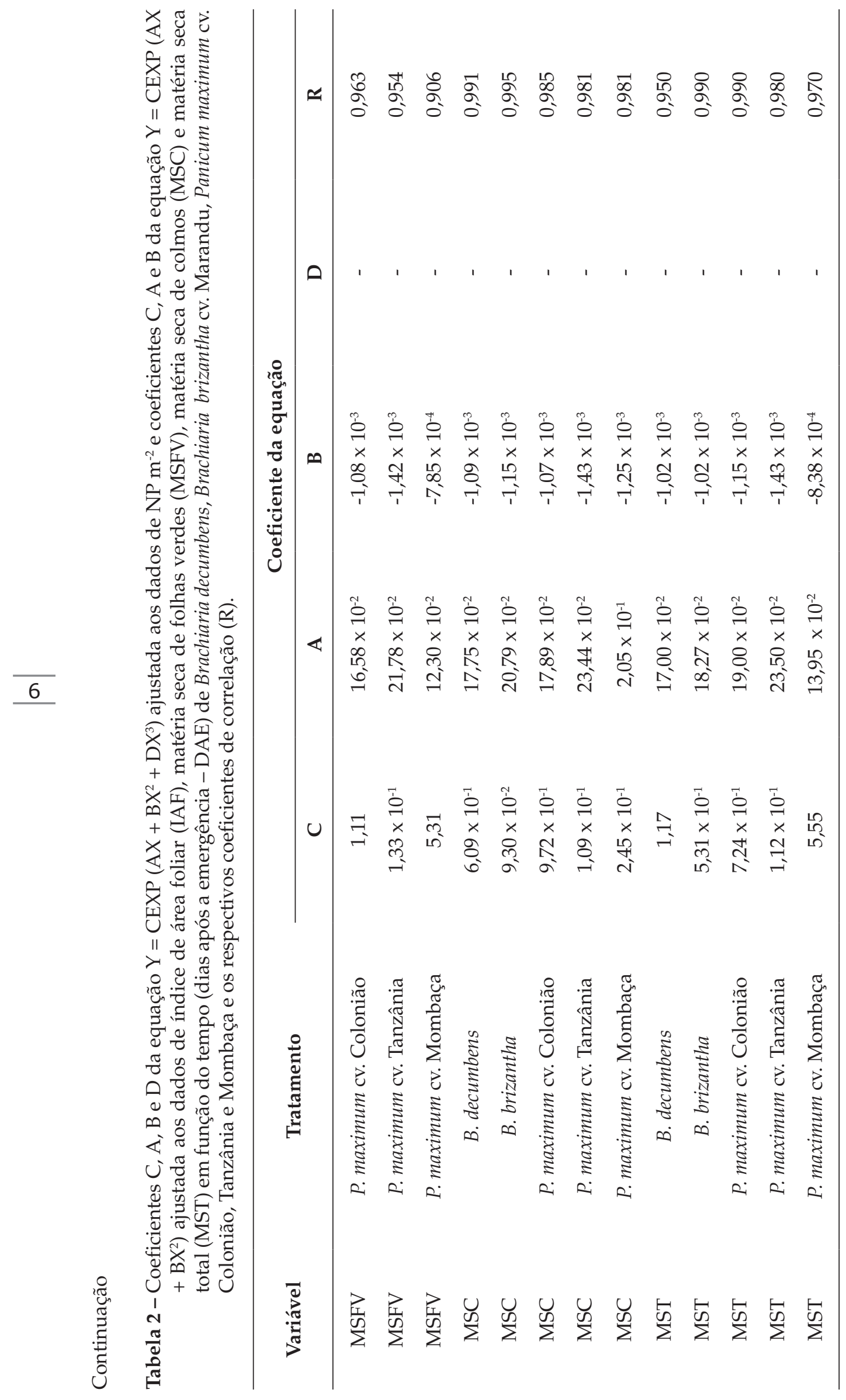




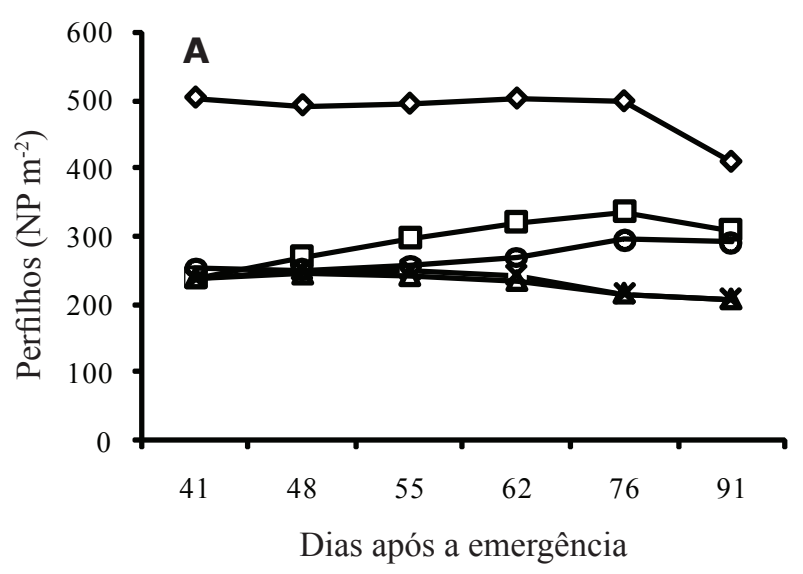

$\checkmark$ B. decumbens $-x-$ Colonião

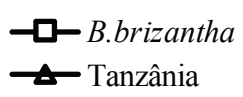

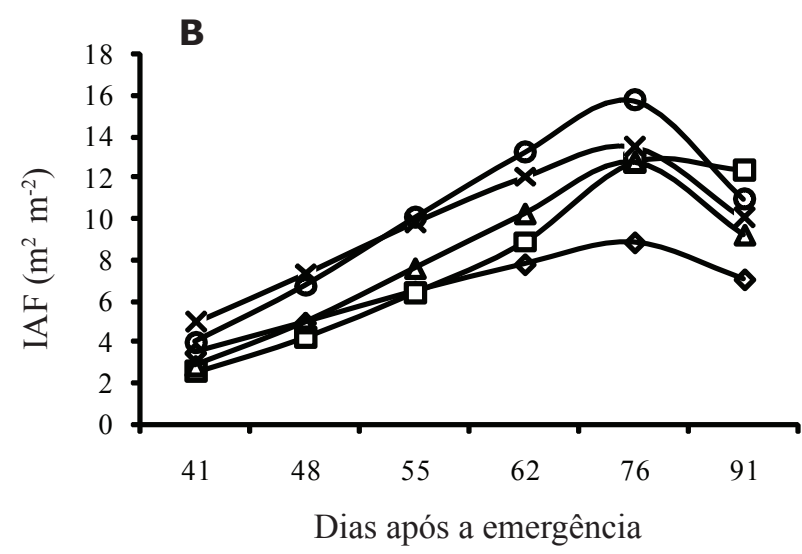

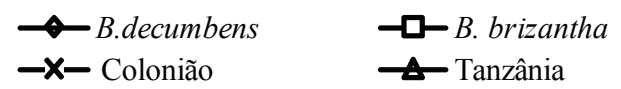

Figura 1 - A. Perfilhos e B. Evolução do índice de área foliar (IAF) com a idade de Brachiaria decumbens, $B$. brizantha cv. Marandu e Panicum maximum cv. Colonião, Tanzânia e Mombaça.

É interessante salientar que, aos $76 \mathrm{DAE}$, embora pelo teste $\mathrm{F}$ tenha ocorrido diferença significativa apenas a $10 \%$ de probabilidade, o teste de Tukey mostrou diferenças entre as médias.

Considerando as equações de regressão, os IAF máximos foram atingidos aos 76 DAE (Figura 1B). O IAF máximo foi de 8,8 para B. decumbens, 12,7 para B. brizantha e cv. Tanzânia, 13,4 para cv. Colonião e 15,8 para Mombaça, o maior. Todas as espécies testadas, com exceção de $B$. brizantha, tiveram suas áreas foliares reduzidas a partir dos 76 DAE. B. brizantha não sofreu redução de área foliar entre os 76 DAE e 91 DAE, por ter atingido a plena floração somente depois de 90 DAE. O ciclo de desenvolvimento completo de algumas dessas forrageiras ultrapassa os 150 DAE, como é o caso de B. brizantha (Braz et al., 2005; Portes et al., 2000). Normalmente, dependendo da condição experimental, tanto o ganho de matéria seca como os IAF continuam crescendo por tempo maior do que o considerado no presente trabalho, cuja última amostragem foi realizada aos 91 DAE. Portanto, dependendo do objetivo do trabalho, é interessante continuar a coletar amostras além dos 91 DAE.

Conceitualmente, o IAF ótimo, o qual não coincide com o IAF máximo, é quando a TCC é máxima (Kvet et al., 1971). Esta, por sua vez, ocorre na data em que o ganho de matéria seca inicia o seu processo de queda, após a fase de crescimento exponencial, isto é, no ponto de inflexão da curva de crescimento em função da idade da planta (Figura 2). Após essa data, a TCC instantânea, que é a tangente à curva de acúmulo de MST no instante $\mathrm{t}$ (DAE), passa a reduzir-se gradualmente até tornar-se nula no ponto em que o ganho de matéria seca alcança o seu máximo. A partir daí, a TCC torna-se negativa, isto é, a senescência de folhas e colmos passa a ser maior do que a formação de novas estruturas. Esta observação tem grande importância no manejo da pastagem, indicando que a sua melhor utilização pelo rebanho deve acontecer no ponto de TCC máxima, antes, portanto, do máximo de matéria seca ter sido alcançado.

De acordo com a definição acima, os IAF ótimos das gramíneas ocorreram aos 62 DAE (Figuras 1B e 2). Nesta data, o IAF ótimo de $B$. decumbens foi de 7,8 , para TCC máxima da MST de $37,1 \mathrm{~g} \mathrm{~m}^{-2} \mathrm{dia}^{-1}$. B. brizantha teve IAF ótimo de 8,9 para TCC máxima de $49,2 \mathrm{~g} \mathrm{~m}^{-2} \mathrm{dia}^{-1}$. No Colonião, para TCC máxima de $54,7 \mathrm{~g} \mathrm{~m}^{-2} \mathrm{dia}^{-1}$, o IAF ótimo foi de 12,0. No Tanzânia, para IAF ótimo de 10,2, a TCC máxima foi de $55,7 \mathrm{~g} \mathrm{~m}^{-2} \mathrm{dia}^{-1}$. No Mombaça, para IAF de 13,2, a TCC foi de 45,4 $\mathrm{g} \mathrm{m}^{-2} \mathrm{dia}^{-1}$.

Em relação à MST da parte aérea da planta, incluindo matéria seca de folhas (verdes e no presente trabalho também foram incluídas as mortas), colmos e inflorescências e descartando-se as raízes, houve diferença $(\mathrm{p} \leq 0,01)$ entre as forrageiras ao serem considerados os 
Tabela 3 - Resumo da análise de variância dos valores originais observados em campo das variáveis medidas das forrageiras.

\begin{tabular}{|c|c|c|c|c|c|c|c|}
\hline \multirow{2}{*}{ Causa de variação } & \multirow{2}{*}{ GL } & \multicolumn{6}{|c|}{ Dias após a emergência } \\
\hline & & 41 & 48 & 55 & 62 & 76 & 91 \\
\hline & & \multicolumn{6}{|c|}{ Número de perfilhos (NP $\left.\mathrm{m}^{-2}\right)$} \\
\hline Forrageira & 4 & $34,1^{* *}$ & $25,06^{* *}$ & $23,62^{* *}$ & $18,95^{* *}$ & $16,42^{* *}$ & $19,10^{* *}$ \\
\hline Bloco & 3 & & & & & & \\
\hline \multirow[t]{2}{*}{ Resíduo } & 12 & & & & & & \\
\hline & \multicolumn{7}{|c|}{ Índice de área foliar (IAF $\left.-\mathrm{m}^{2} \mathrm{~m}^{-2}\right)$} \\
\hline Forrageira & 4 & $2,76^{\mathrm{ns}}$ & $15,3^{* *}$ & $6,58^{* *}$ & $2,22^{\mathrm{ns}}$ & $3,0^{\mathrm{ns}}$ & $4,72^{*}$ \\
\hline Bloco & 3 & & & & & & \\
\hline \multirow[t]{2}{*}{ Resíduo } & 12 & & & & & & \\
\hline & \multicolumn{7}{|c|}{ Matéria seca total (MST - $\mathrm{g} \mathrm{m}^{-2}$ ) } \\
\hline Forrageira & 4 & $20,6^{* *}$ & $15,98^{* *}$ & $7,93^{* *}$ & $1,05^{\mathrm{ns}}$ & $1,17^{\mathrm{ns}}$ & $1,58^{\text {ns }}$ \\
\hline Bloco & 3 & & & & & & \\
\hline \multirow[t]{2}{*}{ Resíduo } & 12 & & & & & & \\
\hline & & \multicolumn{6}{|c|}{ Matéria seca de folhas verdes (MSFV $-\mathrm{g} \mathrm{m}^{-2}$ ) } \\
\hline Forrageira & 4 & $14,62^{* *}$ & $12,23^{* *}$ & $12,15^{* *}$ & $5,17^{* *}$ & $4,33^{* *}$ & $6,72^{* *}$ \\
\hline Bloco & 3 & & & & & & \\
\hline \multirow[t]{2}{*}{ Resíduo } & 12 & & & & & & \\
\hline & & \multicolumn{6}{|c|}{ Matéria seca de colmos (MSC - $\mathrm{g} \mathrm{m}^{-2}$ ) } \\
\hline Forrageira & 4 & $15,44^{* *}$ & $12,62^{* *}$ & $5,66^{* *}$ & $1,04^{\mathrm{ns}}$ & $0,74^{\mathrm{ns}}$ & $0,88^{\text {ns }}$ \\
\hline Bloco & 3 & & & & & & \\
\hline \multirow[t]{2}{*}{ Resíduo } & 12 & & & & & & \\
\hline & \multicolumn{7}{|c|}{ Relação MSFV/MSC } \\
\hline Forrageira & 4 & $31,83^{* *}$ & $3,03^{\text {ns }}$ & $9,41^{* *}$ & $6,37^{* *}$ & $5,25^{*}$ & $1,90^{\text {ns }}$ \\
\hline Bloco & 3 & & & & & & \\
\hline \multirow[t]{2}{*}{ Resíduo } & 12 & & & & & & \\
\hline & & \multicolumn{6}{|c|}{ Matéria seca de folhas mortas (MSFM - $\mathrm{g} \mathrm{m}^{-2}$ ) } \\
\hline Forrageira & 4 & $0,23^{\text {ns }}$ & $4,38^{*}$ & $7,98^{* *}$ & $8,75^{* *}$ & $2,56^{\mathrm{ns}}$ & $1,42^{\text {ns }}$ \\
\hline Bloco & 3 & & & & & & \\
\hline Resíduo & 12 & & & & & & \\
\hline $\mathrm{CV} \% \mathrm{NP}$ & & 13,75 & 13,73 & 14,50 & 16,31 & 18,12 & 13,76 \\
\hline $\mathrm{CV} \% \mathrm{IAF}$ & & 27,70 & 18,38 & 21,18 & 23,38 & 21,43 & 17,68 \\
\hline CV \% MST & & 17,37 & 16,84 & 24,50 & 23,12 & 29,86 & 22,91 \\
\hline CV \% MSFV & & 16,60 & 21,57 & 22,05 & 19,62 & 25,10 & 17,58 \\
\hline $\mathrm{CV} \% \mathrm{MSC}$ & & 19,82 & 18,37 & 29,57 & 28,23 & 30,77 & 26,56 \\
\hline CV \% MSFV / MSC & & 9,23 & 21,40 & 15,22 & 19,58 & 15,24 & 19,30 \\
\hline CV \% MSFM & & 151,30 & 52,11 & 38,45 & 38,13 & 41,65 & 54,33 \\
\hline
\end{tabular}

ns, ${ }^{*} \mathrm{e}^{* *}$, não significativo, significativo a $5 \%$ e a $1 \%$ de probabilidade, respectivamente. 
Tabela 4 - Número de perfilhos (NP), índice de área foliar (IAF), matéria seca de folhas verdes (MSFV), matéria seca de colmos (MSC) e matéria seca total (MST) de cinco forrageiras.

\begin{tabular}{|c|c|c|c|c|c|}
\hline & \multicolumn{5}{|c|}{ Forrageira $^{1}$} \\
\hline & 1 & 2 & 3 & 4 & 5 \\
\hline DAE & \multicolumn{5}{|c|}{ Número de perfilhos $\left(\mathrm{NP} \mathrm{m}^{-2}\right)$} \\
\hline 41 & $501 \mathrm{a}$ & $239 \mathrm{~b}$ & $235 \mathrm{~b}$ & $234 \mathrm{~b}$ & $249 \mathrm{~b}$ \\
\hline 48 & $493 \mathrm{a}$ & $265 \mathrm{~b}$ & $255 \mathrm{~b}$ & $256 \mathrm{~b}$ & $257 \mathrm{~b}$ \\
\hline 55 & $499 \mathrm{a}$ & $300 \mathrm{~b}$ & $247 \mathrm{~b}$ & $236 \mathrm{~b}$ & $262 b$ \\
\hline 62 & $493 \mathrm{a}$ & $322 \mathrm{~b}$ & $239 \mathrm{~b}$ & $229 \mathrm{~b}$ & $257 \mathrm{~b}$ \\
\hline 76 & $501 \mathrm{a}$ & $334 \mathrm{~b}$ & $218 \mathrm{~b}$ & $219 \mathrm{~b}$ & $301 \mathrm{~b}$ \\
\hline 91 & $409 \mathrm{a}$ & $308 \mathrm{~b}$ & $208 c$ & $206 c$ & $265 \mathrm{bc}$ \\
\hline DAE & \multicolumn{5}{|c|}{ Índice de área foliar (IAF $\left.\mathrm{m}^{2} \mathrm{~m}^{-2}\right)$} \\
\hline 41 & $2,4 \mathrm{a}$ & $2,8 \mathrm{a}$ & $4,5 \mathrm{a}$ & $2,5 \mathrm{a}$ & $3,2 \mathrm{a}$ \\
\hline 48 & $4,4 \mathrm{~cd}$ & $3,2 \mathrm{~d}$ & $7,4 \mathrm{ab}$ & $5,7 \mathrm{bc}$ & $8,2 \mathrm{a}$ \\
\hline 55 & $8,1 \mathrm{~b}$ & $7,7 \mathrm{~b}$ & $12,0 \mathrm{ab}$ & $7,5 \mathrm{~b}$ & $13,0 \mathrm{a}$ \\
\hline 62 & $7,6 \mathrm{a}$ & $9,1 \mathrm{a}$ & $11,7 \mathrm{a}$ & $11,3 \mathrm{a}$ & $11,3 \mathrm{a}$ \\
\hline 76 & $7,7 \mathrm{~b}$ & $12,1 \mathrm{ab}$ & $11,1 \mathrm{ab}$ & $10,5 \mathrm{ab}$ & $13,1 \mathrm{a}$ \\
\hline 91 & $7,4 \mathrm{~b}$ & $12,5 \mathrm{a}$ & $10,6 \mathrm{ab}$ & $9,9 \mathrm{ab}$ & $12,0 \mathrm{a}$ \\
\hline DAE & \multicolumn{5}{|c|}{ Relação MSFV/MSC } \\
\hline 41 & $0,9 \mathrm{c}$ & $1,5 \mathrm{~b}$ & $2,0 \mathrm{a}$ & $1,6 \mathrm{~b}$ & $1,6 \mathrm{~b}$ \\
\hline 48 & $0,8 \mathrm{a}$ & $1,1 \mathrm{a}$ & $1,3 \mathrm{a}$ & $1,3 \mathrm{a}$ & $1,3 \mathrm{a}$ \\
\hline 55 & $0,6 \mathrm{~b}$ & $1,1 \mathrm{a}$ & $1,2 \mathrm{a}$ & $1,2 \mathrm{a}$ & $1,1 \mathrm{a}$ \\
\hline 62 & $0,5 \mathrm{~b}$ & $1,0 \mathrm{a}$ & $1,0 \mathrm{a}$ & $0,9 \mathrm{a}$ & $0,7 \mathrm{ab}$ \\
\hline 76 & $0,5 \mathrm{~b}$ & $0,7 \mathrm{a}$ & $0,7 \mathrm{a}$ & $0,6 a b$ & $0,7 \mathrm{a}$ \\
\hline 91 & $0,5 \mathrm{a}$ & $0,7 \mathrm{a}$ & $0,5 \mathrm{a}$ & $0,5 \mathrm{a}$ & $0,6 \mathrm{a}$ \\
\hline DAE & \multicolumn{5}{|c|}{ Matéria seca de folhas verdes (MSFV $-\mathrm{g} \mathrm{m}^{-2}$ ) } \\
\hline 41 & $121,5 \mathrm{bc}$ & $112,0 \mathrm{bc}$ & $155,0 \mathrm{ab}$ & $85,0 \mathrm{c}$ & $195,0 \mathrm{a}$ \\
\hline 48 & $175,8 \mathrm{bc}$ & $129,2 \mathrm{c}$ & $238,1 \mathrm{ab}$ & $189,3 \mathrm{bc}$ & $342,4 \mathrm{a}$ \\
\hline 55 & $263,0 \mathrm{c}$ & $313,7 \mathrm{bc}$ & $493,7 \mathrm{ab}$ & $260,4 \mathrm{c}$ & 583,4 a \\
\hline 62 & $297,1 \mathrm{~b}$ & $439,0 \mathrm{ab}$ & $464,6 \mathrm{ab}$ & $565,9 \mathrm{a}$ & $409,2 \mathrm{ab}$ \\
\hline 76 & $323,0 \mathrm{~b}$ & $603,0 \mathrm{ab}$ & $550,7 \mathrm{ab}$ & $416,3 \mathrm{ab}$ & $635,5 \mathrm{a}$ \\
\hline 91 & $364,6 \mathrm{c}$ & 678,7 a & $539,5 \mathrm{abc}$ & $468,1 \mathrm{bc}$ & $600,9 \mathrm{ab}$ \\
\hline DAE & \multicolumn{5}{|c|}{ Matéria seca de colmos (MSC - $\mathrm{g} \mathrm{m}^{-2}$ ) } \\
\hline 41 & $141,4 \mathrm{a}$ & $74,0 \mathrm{c}$ & $79,6 \mathrm{bc}$ & $52,3 \mathrm{c}$ & $121,1 \mathrm{ab}$ \\
\hline 48 & $228,9 \mathrm{ab}$ & $114,9 \mathrm{c}$ & $186,1 \mathrm{bc}$ & $152,2 \mathrm{bc}$ & $273,5 \mathrm{a}$ \\
\hline 55 & $435,7 \mathrm{ab}$ & $284,7 \mathrm{~b}$ & $425,3 \mathrm{ab}$ & $233,7 \mathrm{~b}$ & $583,5 \mathrm{a}$ \\
\hline 62 & $600,5 \mathrm{a}$ & 453,8 a & 465,9 a & 623,5 a & $572,0 \mathrm{a}$ \\
\hline 76 & $716,7 \mathrm{a}$ & 856,6 a & 839,1 a & $695,9 \mathrm{a}$ & $956,4 \mathrm{a}$ \\
\hline 91 & 801,5 a & $1.077,7 \mathrm{a}$ & $1.032,0 \mathrm{a}$ & 880,7 a & $1.052,3 \mathrm{a}$ \\
\hline DAE & \multicolumn{5}{|c|}{ Matéria seca total (MST $-\mathrm{g} \mathrm{m}^{-2}$ ) } \\
\hline 41 & $262,9 \mathrm{~b}$ & $186,0 \mathrm{bc}$ & $235,0 \mathrm{~b}$ & $137,5 \mathrm{c}$ & $390,0 \mathrm{a}$ \\
\hline 48 & $404,7 \mathrm{~b}$ & $244,2 \mathrm{c}$ & $424,3 \mathrm{~b}$ & 341,6 bc & $616,0 \mathrm{a}$ \\
\hline 55 & $713,2 \mathrm{~b}$ & $598,4 \mathrm{~b}$ & $919,0 \mathrm{ab}$ & $494,1 \mathrm{~b}$ & $1.166,9 \mathrm{a}$ \\
\hline 62 & $936,2 \mathrm{a}$ & 892,8 a & 936,6 a & $1.190,3 \mathrm{a}$ & $1.008,8 \mathrm{a}$ \\
\hline 76 & $1.130,7 \mathrm{a}$ & $1.459,7 \mathrm{a}$ & $1.492,6 \mathrm{a}$ & $1.212,0 \mathrm{a}$ & $1.688,4$ \\
\hline 91 & $1.225,0 \mathrm{a}$ & $1.797,6 \mathrm{a}$ & $1.696,5 \mathrm{a}$ & $1.525,1 \mathrm{a}$ & $1.728,2$ \\
\hline
\end{tabular}

${ }^{1}$ Forrageira: 1. Brachiaria decumbens; 2. B. brizantha; 3. Panicum maximum cv. Colonião; 4. P. maximum cv. Tanzânia; 5. P. maximum cv. Mombaça.

Médias dos valores originais observados em campo, seguidas da mesma letra na linha não diferem entre si pelo teste de Tukey a $5 \%$ de probabilidade. 


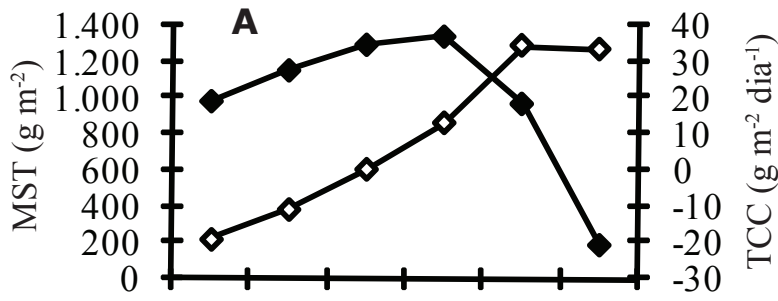

$\begin{array}{llllll}41 & 48 & 55 & 62 & 76 & 91\end{array}$

Dias após a emergência

$$
\leadsto \text { MST } \sim \text { TCC }
$$

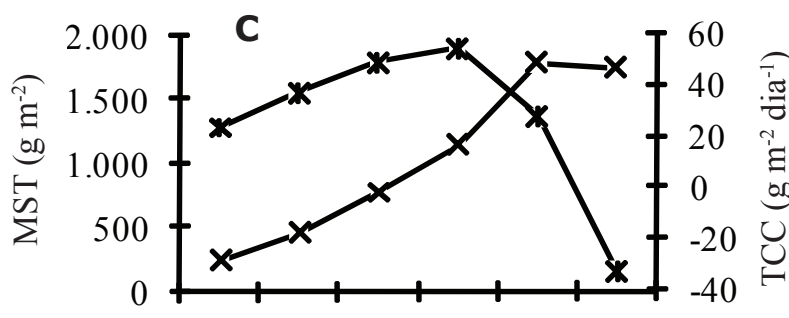

$\begin{array}{llllll}41 & 48 & 55 & 62 & 76 & 91\end{array}$

Dias após a emergência

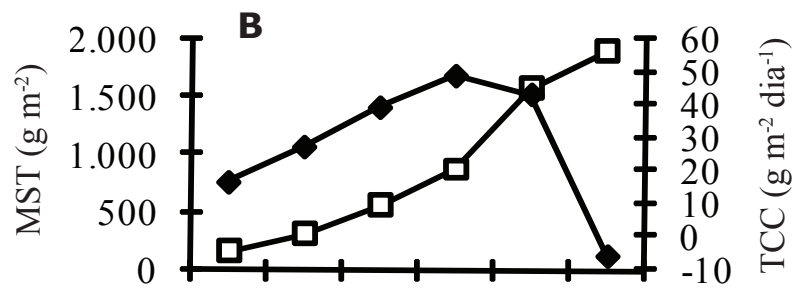

$\begin{array}{llllll}41 & 48 & 55 & 62 & 76 & 91\end{array}$

Dias após a emergência
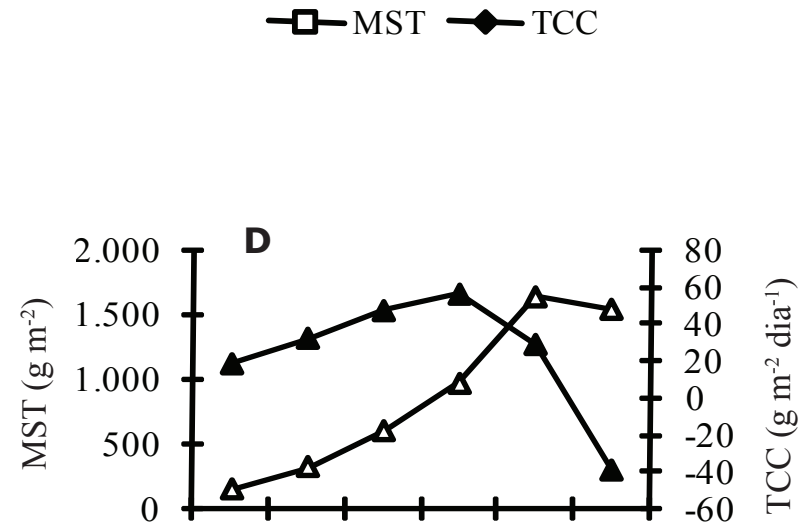

$\begin{array}{llllll}41 & 48 & 55 & 62 & 76 & 91\end{array}$

Dias após a emergência

$\sim \mathrm{MST} \sim \mathrm{MCC}$

$$
-x-\operatorname{MST}-x-\text { TCC }
$$

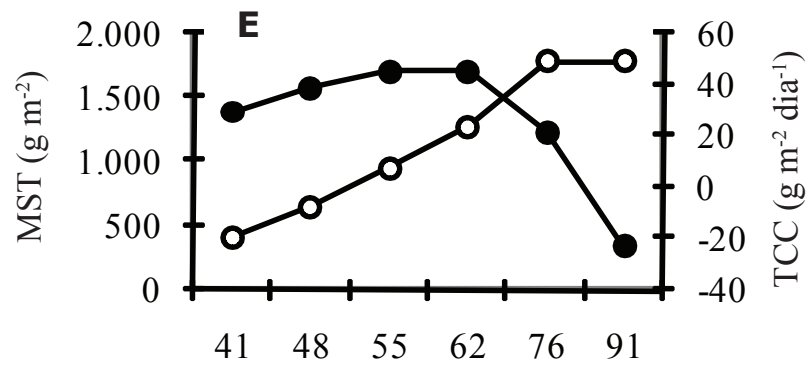

Dias após a emergência

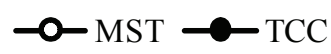

Figura 2 - Evolução da matéria seca total da parte aérea (MST) e das respectivas taxas de crescimento da cultura (TCC) em A. Brachiaria decumbens, B. B. brizantha cv. Marandu, C. Panicum maximum cv. Colonião, D. P. maximum Cv. Tanzânia e E. P. maximum cv. Mombaça.

valores originais obtidos em campo, aos $41 \mathrm{DAE}$, 48 DAE e 55 DAE; entretanto, não houve diferenças aos 62 DAE, 76 DAE e 91 DAE (Tabela 3). Porém, ao se considerar as equações ajustadas aos dados, percebe-se que a menor produção máxima foi de B. decumbens, com $1.289 \mathrm{~g} \mathrm{~m}^{-2}$ aos 76 DAE (Figura 3A). Colonião e Mombaça tiveram as maiores produções aos $76 \mathrm{DAE}$, alcançando valores aproximados de $1.780 \mathrm{~g} \mathrm{~m}^{-2}$ cada. Após ter crescido menos do que Colonião e Mombaça até os 62 DAE, B. brizantha acelerou seu crescimento e teve produção máxima 
de $1.894 \mathrm{~g} \mathrm{~m}^{-2}$ aos $91 \mathrm{DAE}$, ultrapassando as outras duas. Tanzânia teve produção máxima aos $76 \mathrm{DAE}$, chegando a $1.636 \mathrm{~g} \mathrm{~m}^{-2}$.

Por volta dos $80 \mathrm{DAE}$, as TAL para todas as forrageiras tornaram-se nulas (Figura 3B) e negativas a partir desta data, evidenciando que a fixação fotossintética de $\mathrm{CO}_{2}$ pelas plantas foi ultrapassada pela respiração total (considerando apenas a parte aérea), com repercussão nos IAF e MST (Figuras 1B e 3A).

A literatura tem mostrado diversidade em resultados encontrados para MST. Trabalhando com B. brizantha e Mombaça, Braz et al. (2005) encontraram produção máxima de 23,6 $\mathrm{t} \mathrm{ha}^{-1}$ (ou $2.360 \mathrm{~g} \mathrm{~m}^{-2}$ ) aos 107 DAE para a braquiária e de 18,2 $\mathrm{t} \mathrm{ha}^{-1}$ (ou $1.820 \mathrm{~g} \mathrm{~m}^{-2}$ ) aos 120 DAE para Mombaça. Portes et al. (2000) encontraram 19,6 $\mathrm{t} \mathrm{ha}^{-1}$ para $B$. brizantha aos 117 DAE. Botrel et al. (1999) encontraram $16.379 \mathrm{~kg} \mathrm{ha}^{-1}$ ao ano para $B$. brizantha e $14.043 \mathrm{~kg} \mathrm{ha}^{-1}$ para $B$. decumbens. O fato de no presente experimento a maioria das gramíneas ter alcançado produções máximas de matéria seca da parte aérea aos 76 DAE e $B$. Brizantha aos 91 DAE é explicado pelo acamamento ocorrido em Mombaça e à interrupção das amostragens antes do início da senescência total dos capins (amadurecimento pleno).

A maior produção de MST de B. brizantha pode estar relacionada ao seu ciclo mais longo, uma vez que só alcançou floração plena aos 90 DAE.

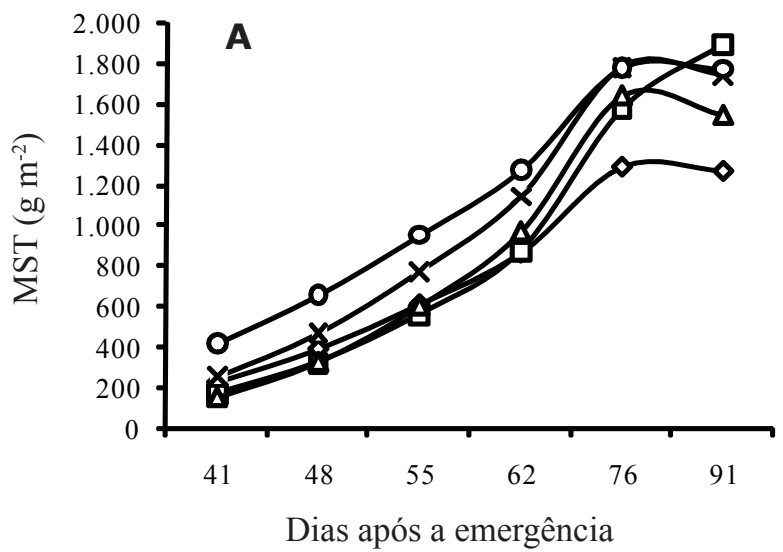

A quantidade de folhas verdes no momento de introduzir os animais na pastagem é muito importante, pois eles dão preferência a essas folhas, normalmente deixando intacta a maior parte dos colmos. Verificando os dados apresentados na Tabela 3, constata-se que houve diferença na produção de folhas verdes $(p \leq 0,01)$ entre as forrageiras em todas as datas avaliadas. Pela Tabela 4, percebe-se que houve predominância de Mombaça até os 55 DAE, com diminuição desta predominância a partir de então.

Considerando-se os valores observados em campo, as MSC produzidas pelas forrageiras foram diferentes aos $41 \mathrm{DAE}, 48 \mathrm{DAE}$ e 55 DAE ( $p \leq 0,01)$. Para as demais datas, não houve diferenças significativas (Tabela 3). Tomando por base as equações ajustadas e considerando o crescimento dos diferentes órgãos das cinco gramíneas avaliadas, o crescimento dos colmos sobrepôs o das folhas, a partir dos 41 DAE em B. decumbens e $P$. maximum $\mathrm{cv}$. Tanzânia e Colonião, 55 DAE em Mombaça e 62 DAE em B. brizantha (Figura 4).

$\mathrm{O}$ incremento no crescimento foliar diminuiu em benefício do crescimento dos colmos e inflorescências, evidenciando que, na alocação de fotoassimilados provenientes da fotossíntese, os colmos e as inflorescências estão sendo beneficiados. A alocação para os colmos é uma estratégia da planta para acumular massa, uma vez que o excesso de

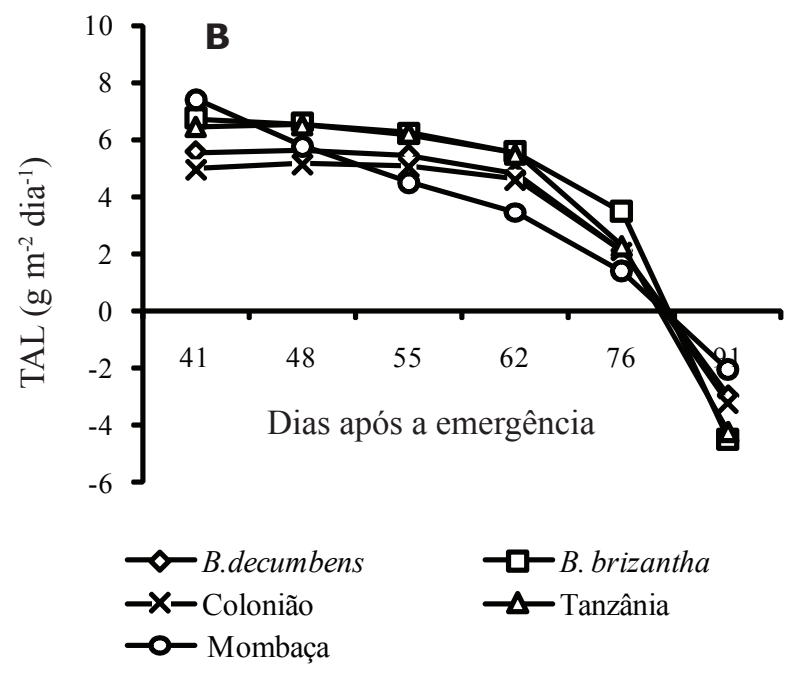

Figura 3 - Evolução de A. Matéria seca total (MST) e B. Taxa assimilatória líquida (TAL) em Brachiaria decumbens, B. brizantha cv. Marandu e Panicum maximum cv. Colonião, Tanzânia e Mombaça. 

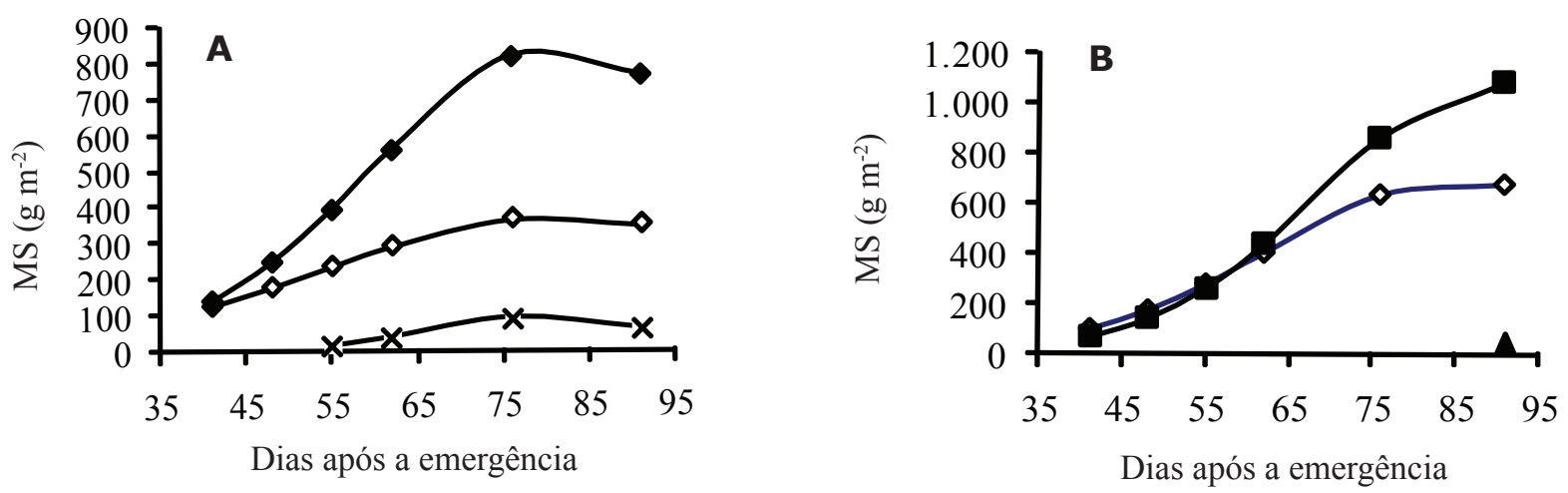

$\multimap$ MSFV $-x-$ MSInf $\multimap$ MSC

$\sim$ MSFV $\rightarrow$ MSC $\rightarrow$ MSInf

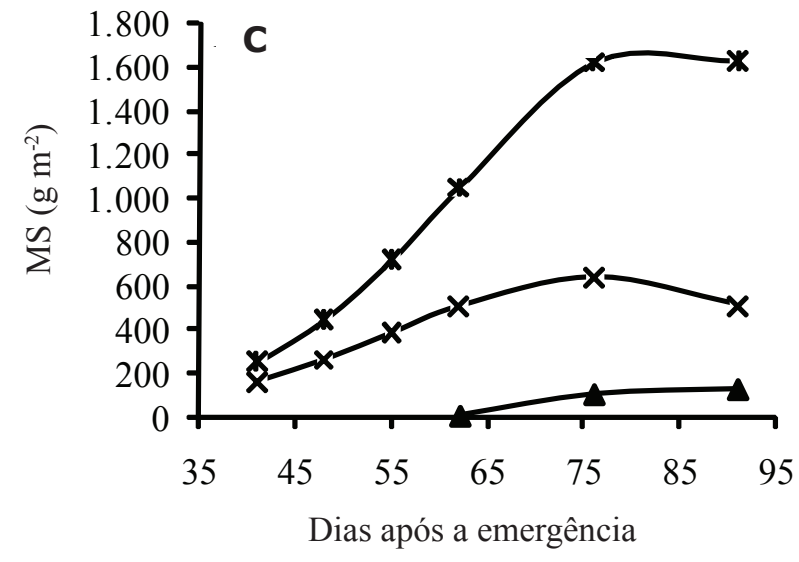

$\rightarrow-M S F V \rightarrow-M S C \rightarrow$ MSInf

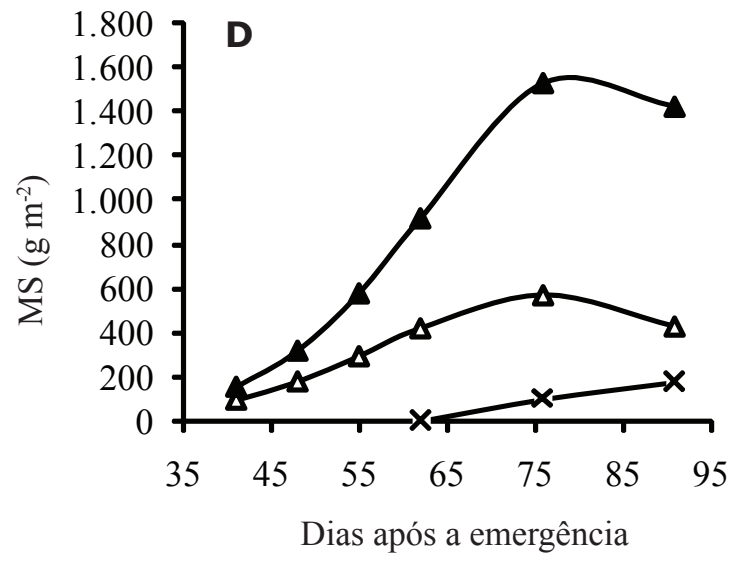

$\rightarrow$ MSFV $\rightarrow$ MSC $\rightarrow-\mathrm{MSInf}$

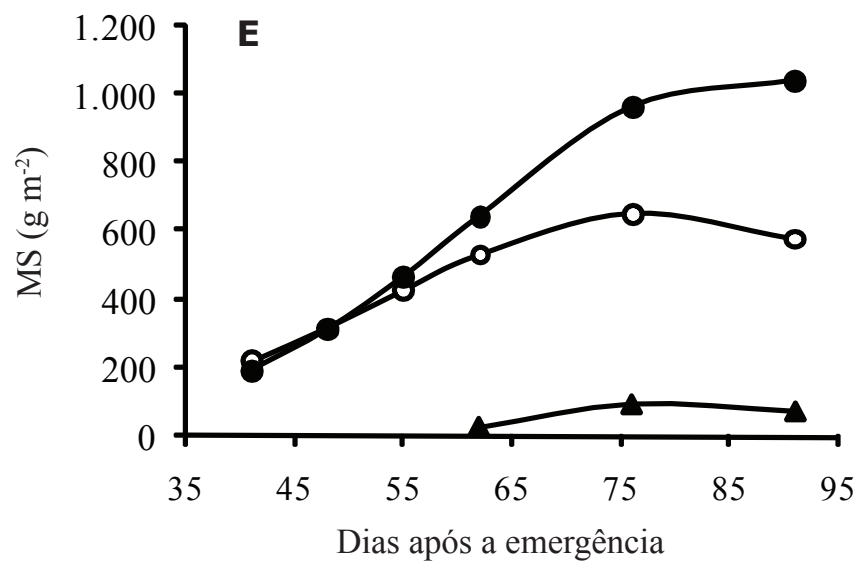

$\multimap$ MSFV $\longrightarrow$ MSC $\longrightarrow$ MSInf

Figura 4 - Evolução com a idade da matéria seca das folhas verdes (MSFV), matéria seca dos colmos (MSC) e matéria seca das inflorescências (MSInf) em A. Brachiaria decumbens, B. B. brizantha cv. Marandu, C. Panicum maximum cv. Colonião, D. P. maximum cv. Tanzânia e E. P. maximum cv. Mombaça. 
folhas causa autossombreamento, reduzindo a fotossíntese total da planta. Este fato fica evidenciado ao se observar a TAL ao longo do ciclo das plantas (Figura 3B). A TAL é uma estimativa da fotossíntese líquida (fotossíntese menos respiração) e, portanto, dependente da luz. O aumento no IAF acarreta sobreposição de folhas com consequente incremento no autossombreamento e redução da TAL.

As gramíneas $\mathrm{C} 4$ que se desenvolvem em condições de alta irradiância têm altas taxas de fixação fotossintética do $\mathrm{CO}_{2}$. B. brizantha chega a fixar $42 \mu \mathrm{mol}$ de $\mathrm{CO}_{2} \mathrm{~m}^{-2} \mathrm{~s}^{-1}$ e B. humidicola, $41 \mu \mathrm{mol}$ de $\mathrm{CO}_{2} \mathrm{~m}^{-2} \mathrm{~s}^{-1}$ (Dias Filho, 2002). Essas altas taxas fotossintéticas decorrem das características intrínsecas, anatômicas e fisiológicas das plantas C4 (Portes et al., 2003; Taiz \& Zeiger, 2008) e repercutem na produção de fitomassa (Braz et al., 2005; Portes et al., 2000).

As relações MSFV / MSC das forrageiras foram diferentes aos $41 \mathrm{DAE}, 55 \mathrm{DAE}, 62 \mathrm{DAE}$ $(p \leq 0,01)$ e 76 DAE ( $p \leq 0,05)$, mas não aos 48 DAE e 91 DAE (Tabela 3). Em geral, $B$. decumbens foi a que apresentou a menor relação, não havendo diferenças entre as demais (Tabela 4).

As quantidades de folhas mortas medidas ao longo da ontogenia das plantas apresentaram diferenças entre as forrageiras aos $48 \mathrm{DAE}$ $(p \leq 0,05)$ e aos 55 DAE e 62 DAE $(p \leq 0,01)$, mas nenhuma diferença aos 76 DAE e 91 DAE (Tabela 3). Os CV foram demasiadamente elevados, resultado da grande disparidade no número de folhas que entram em senescência entre as diferentes repetições.

As divergências nos resultados encontrados na literatura disponível, sobre as produções de pastagens em função da ontogenia das plantas, podem ser explicadas considerando diferenças metodológicas, como as técnicas de amostragem em campo e número de amostragens. Deve-se considerar, também, a fertilidade natural do solo em que cada experimento foi conduzido e, em especial, a adubação aplicada e a época (estação) em que o experimento está sendo conduzido.

\section{Conclusões}

Das gramíneas forrageiras analisadas e nas condições experimentais emprega- das, $B$. decumbens foi a que mais produziu perfilhos, as menores MST e TCC máxima instantânea. Mombaça produziu a maior área foliar, aos 76 DAE. Colonião e Tanzânia apresentaram as maiores TCC máximas instantâneas aos 62 DAE. A matéria seca máxima foi alcançada aos 91 DAE por B. brizantha. Modelos matemáticos do tipo exponencial cúbico são os mais indicados em simulações de produção de perfilhos, enquanto os do tipo exponencial quadrático são os mais indicados em simulações de IAF, MSFV, MSC e MST para as gramíneas forrageiras $B$. decumbens, B. brizantha, P. maximum cv. Colonião, Tanzânia e Mombaça.

\section{Agradecimentos}

Ao Conselho Nacional de desenvolvimento Científico (CNPq), pelas bolsas outorgadas aos autores. Aos revisores, pelas sugestões que tornaram este artigo melhor.

\section{ReferênCIAS}

Andrade, J. B., R. P. Benintende, E. Ferrari Júnior, V. T. Paulino, W. Henrique, J. C. Werner \& H. B. Mattos. 1996. Efeito da adubação nitrogenada e potássica na produção e composição da forragem de Brachiaria ruziziensis. Pesq. Agropec. Bras. 31: 617-620.

Bernardo, E. R. de A., V. de F. Rocha, O. Puga \& R. A. Silva. 2003. Espécies de cigarrinhasdas-pastagens (Hemiptera: Cercopidae) no meio-norte do Mato Grosso. Pastagens (Hemiptera: cercopidae) no meio-norte do Mato Grosso. Ciênc. Rural 33: 369-371.

Blackman, V. H. 1919. The compound interest law and plant growth. Ann. Bot. 33: 353360.

Boddey, R.M., R. Macedo, R. M. Tarré, E. Ferreira, O. C. Oliveira, C. P. Rezende, R. B. Cantarutti, J. M. Pereira, B. J. R. Alves \& S. Urquiaga. 2004. Nitrogen cycling in Brachiaria pastures: the key to understanding the process of pasture decline. Agric. Ecosyst. Environ. 103:389-403.

Botrel, M. de A., M. J. Alvim \& D. F. Xavier. 1999. Avaliação de gramíneas forrageiras na região sul de Minas Gerais. Pesq. Agropec. Bras. 34: 683-689. 
Braz, A. J. B. P., H. J. Kliemann \& P. M. Silveira. 2005. Produção de fitomassa de espécies de cobertura em latossolo vermelho distroférrico. Pesq. Agropec. Trop. 35: 55-64.

Canto, M. W., C. C. Jobim, E. Gasparino \& A. R. Hoesch. 2008. Características do pasto e acúmulo de forragem em capimtanzânia submetidos a alturas de manejo do pasto. Pesq. Agropec. Bras. 43: 429435.

Dias Filho, M. B. 2002. Photosynthetic light response of the $\mathrm{C} 4$ grasses Brachiaria brizantha and $B$. humidicola under shade. Scient. Agric. 59: 65-68.

Estrada, C. L. H., D. Nascimento Junior \& A. J. Regazzi. 1991. Efeito do número e tamanho do quadrado nas estimativas pelo Botanal da composição botânica e disponibilidade de matéria seca de pastagens cultivadas. Rev. Soc. Bras. Zootec. 20: 483-493.

Gerdes, L., J. C. Werner, M. T. Colozza, D. D. Carvalho \& E. A. Schammas. 2000. Avaliação de características agronômicas e morfogênicas das gramíneas forrageiras Marandu, Sectária e Tanzânia aos 35 dias se crescimento nas estações do ano. Rev. Bras. Zootec. 29: 947-954.

Gomide, C. A. M. \& J. A. 1996. Gomide. Morfogênese e análise de crescimento de cultivares de Panicum maximum. In: $33^{\text {a }}$ Reunião Anual da Sociedade Brasileira de Zootecnia, Fortaleza, CE. Anais. p. 403405.

Kvet, J., J. P. Ondok, J. Nečas \& P. G. Jarvis. 1971. Methods of growth analysis, p. 343391. In: Z. Restak, J. Catsky \& P. G. Jarvis (Eds), Plant photosynthetic production: manual of methods. The Hague, W. Junk.
Paciullo, D. S. C., C. A. B. Carvalho, L. J. M. Aroeira, M. F. Morenz, F. C. F. Lopes \& R. O. P. Rosiello. 2007. Morfofisiologia e valor nutritivo do capim-braquiária sob sombreamento natural e a sol pleno. Pesq. Agropec. Bras. 4: 573-579.

Portes, T. A. \& L. G. Castro Júnior. 1991. Análise de crescimento de plantas: um programa computacional auxiliar. Rev. Bras. Fisiol. Veg. 3: 53-56.

Portes, T. A., S. I. C. Carvalho, I. P. Oliveira \& J. Kluthcouski. 2000. Análise de crescimento de uma espécie de braquiária consorciada com as culturas de milho, sorgo, milheto e arroz. Pesq. Agropec. Bras. 35: 1349-1358.

Portes, T. A., S. I. C. Carvalho \& J. Kluthcouski. 2003. Aspectos fisiológicos das plantas cultivadas e análise de crescimento da braquiária consorciada com cereais, $p$. 304-329. v. 1. In: J. Kluthcouski, L. F. Stone \& H. Aidar (Eds). Integração lavourapecuária. 1 ed. Goiânia, Talento Gráfica e Editora.

Taiz, L. \& Zeiger, E. 2008. Plant physiology. The Benjamin Cummings Publishing Company, Redwood.

Zimmer, A. H. \& E. S. Corrêa. 1993. A pecuária nacional, uma pecuária de pasto. In: $1^{\circ}$ Encontro sobre recuperação de pastagens, Nova Odessa, SP. Anais. p. 1-25.

Recebido em 8.V.2009

Aceito em 15.XII.2009 